\title{
A CASE REPORT ON ISOLATED HEMATURIA WITH ANEMIA DUE TO SCHISTOSOMA HAEMATOBIUM
}

\author{
SAGAR PAMU, LAKSHMI THAKKALAPALLY, BALAKRISHNA VUYYALA \\ Guru Nanak Institutions Technical Campus, School of Pharmacy, Ibrahimpatnam, Telangana, India \\ Email: dr.sagar@live.com
}

Received: 05 Jul 2017 Revised and Accepted: 21 Sep 2017

\section{ABSTRACT}

An unsual case in India was reported with an Isolated Hematuria with Anemia due to Schistosoma Haematobium infection. A male North African patient aged $22 \mathrm{y}^{*}$ admitted in hospital in Hyderabad with chief complaints of hematuria with dysuria, fever with night sweats, and shortness of breath during exercise. His skin appears as pale. His history known that he came to India for his academics. He has a habit of swimming in lake at his country. He has no known past medical history and medication history. His blood reports were found to be low hemoglobin levels and low Red blood cells (RBCs) count. His urine analysis detected with reddish colored erythrocytes and crystals with an absence of proteins and casts. Microscopic examination of urine detects $S$. haematobium eggs by using repeated concentration techniques.

Keywords: Isolated Hematuria, Schistosoma Haematobium, Bladder ulceration, Anemia, Pallor

(C) 2017 The Authors. Published by Innovare Academic Sciences Pvt Ltd. This is an open access article under the CC BY license (http://creativecommons.org/licenses/by/4.0/) DOI: http://dx.doi.org/10.22159/ijpps.2017v9i11.21137

\section{INTRODUCTION}

The risk of Isolated Hematuria with $S$. haematobium has been considered from the review of previous reports. The purpose to report this case is due to an unusual and migrant case in India from Africa. The case was reported with $S$. haematobium causes an Isolated Hematuria with pallor where it leads to form a condition of anemia. The case report was collected from the tertiary care hospital in Hyderabad where the patient belonged to the African country.

Hematuria is a presence of RBCs in urine more than 3 RBCs per high power field on urine sediment examination. Hematuria can be of Gross Hematuria which appears red bloody colored which is visible (or) Microscopic Hematuria appears discolorations which are not visible. Isolated Hematuria is with a presence of urine RBCs but with an absence of other abnormalities like protienuria, casts etc [1]. Red colored urine is not always due to RBCs but may also due to hemoglobin (or) myoglobin, porphyria, foods (beetroot, food colours) and Drugs (phenazopyridine, sometimes with cascara, methyldopa, senna etc.) in urine [1]. The pathogenic mechanism is an entry of RBCs in urine from anywhere along the urinary tract i.e. from the kidneys, collecting ducts and ureters, prostate, urinary bladder and urethra [2].

S. haematobium, a parasitic fluke of the genus Schistosoma can invade the urinary tract that causes Isolated Hematuria. Although the other causes like UTI, prostatis, urinary calculi, cancer, glomerular disorders, mycobacterium tuberculosis and vigorous exercise are also concern reasons to occur hematuria [3].

There are different species of Schistosomiasis like Schistosoma Mansoni and Schistosoma Japanicum causes bloody diarrhea but $S$. Haematobium causes hematuria [4]. S. Heamatobium infection occurs in endemic areas [5], the disease may be imported through travelers and migrants [6] and also can spread with the contact of water through swimming, boating, and water skiing. The World Health Organization considers it a significant disease widely distributed over the African continent $[7,8]$ with lesser extent in Turkey, India and parts of Middle East.

Humans are the main reservoirs for $S$. Haematobium species while dogs, cats, rodents, pigs, hoses and goats are reservoirs for Schistosoma Japanicum and dogs for Schistosoma Mekongi [9]. S. haematobium infection occurs due to urine contamination which contains eggs and releases miracidia in lake which penetrates in snail and progresses two generations of sporocytes to become cercariae. The free-swimming cercariae penetrate in human skin and transforms into schistosomula within few minutes which travel through the bloodstream to the liver, where they mature into adults. The paired adults migrate into intestinal veins or the GU venous plexus where they lay eggs and appear in urine within 1-3 mo [10].

The signs and symptoms with $S$. Haematobium infection occurs in bladder cause ulcerations and leads to dysuria, hematuria, and urinary frequency, if untreated it leads to development of chronic cystitis. Strictures may lead to hydrouretic and hydronephrosis. Papillomatous masses in the bladder are common and squamous cell carcinoma may develop.

A diagnosis can be done by microscopic examination of urine samples for eggs by using repeated concentration techniques [11, 12]. A praziquantel an antihelmintihic drug works by killing parasites can be used for the treatment of S. Haematobium infection [13-15]

\section{CASE REPORT}

A male African patient aged $22 \mathrm{y}^{*}$ was admitted in the tertiary care hospital in Hyderabad with chief complaints of blood in urine since $10 \mathrm{~d}$ with a painful and difficulty in urination. Sometime the patient felts with urine urgency. He also suffers from fever with night sweats. His history known that the patient came to India for his academics. The patient has a habit of swimming in lake at his country. He feels shortness of breath during exercise. He has no known past medical history and past medication history.

The patient's vital signs were founded with a normal blood pressure and high temperature i.e. $99^{\circ} \mathrm{F}$. The patient's systemic examinations were normal but his skin appears as a pale. He also inspected for rashes and edema but not founded.

The patient's blood picture reports were found to be hemoglobin$10.3 \mathrm{~g} / \mathrm{dl}$, RBC count-4.2 million cells $/ \mu \mathrm{l}$, WBC count-10,000 cells $/ \mathrm{m}^{3}$, Platelet count- 2 lakh cells $/ \mathrm{m}^{3}$.

The patient's urine analysis findings were detected with reddish colored urine with normal sized biconcave shaped erythrocytes and crystals. There was no presence of proteins and casts in the urine sample.

Under microscopic examination of urine, S. Haematobium eggs were detected by using repeated concentration techniques and finally it was confirmed the diagnosis as Hematuria with anemia due to $S$. Haematobium infection. 


\section{DISCUSSION}

The $S$. haematobium infection is an endemic disease can spread through travelers, migrants and with the contact of contaminated water. Here the patient was also an African where his history known with habit of swimming in lakes. The patient felt with the shortness of breath as it can be understood due to low hemoglobin levels and decreased RBCs count where it leads to anemia. The patient's vital signs were observed with high temperature as it indicates the fever and in his systemic examination the skin appears as a pale color as it indicates pallor. His chief complaints like hematuria with painful and difficulty in urination indicates in the reports of urine analysis i.e. reddish colored urine with circular biconcave erythrocytes.

Stool examination should be performed when infection with $S$. mansoni or $S$. japonicum is suspected, and urine examination should be performed if $S$. haematobium is suspected. Eggs can be present in the stool in infections with all Schistosoma species. Here the examination was performed with the patient's urine sample, founded infections with $S$. haematobium (recommended time for collection between noon and 3 PM). Detection was enhanced by centrifugation and examination of the sediment. Quantification is possible by using filtration through a Nucleopore membrane of a standard volume of urine followed by egg counts on the membrane. Tissue biopsy (rectal biopsy for all species and biopsy of the bladder for $S$. haematobium) may demonstrate eggs when stool or urine examinations are negative.

The patient was concluded as anemic patient with the findings of pallor, low hemoglobin levels and decreased RBC's count and his urine sample was observed to be reddish colored with normal sized biconcave shaped erythrocytes and crystals

This case was analyzed with previous studies and it reveals there is a relation between anemia and S. haematobium infection but its mechanism was unclear. Finally this case was understood as Isolated Hematuria with Anemia due to $S$. haematobium infection which is very unusual and lesser extent of its infection in India.

\section{CONCLUSION}

The diagnosis with S. haematobium infection which caused Isolated Hematuria with Anemia was an unusual case report in India. The patient is a migrant who belongs to African country, so care should be taken for its prevention in India by avoiding a bathing or swimming in lakes and by maintaining the sanitary disposal of urine and feces.

\section{ACKNOWLEDGEMENT}

I thankful to the tertiary care hospital in Hyderabad who supports me for the analysis of this case report. I also thankful to Guru Nanak Institutions Technical Campus, School of Pharmacy for the acceptance of facilities required.

\section{AUTHORS CONTRIBUTION}

Sagar Pamu-Identified the case and its analysis was done. Laksmi Thakkalapally-Supported in detail understand of this case and manuscript development. Balakrishna Vuyyala-By understanding its manuscript supported in making edit.

\section{CONFLICT OF INTERESTS}

Declared none

\section{REFERENCES}

1. Tanaka H, Kim ST, Takasugi M, Kuroiwa A. Isolated hematuria in adults: IgA nephropathy is a predominant cause of hematuria compared with thin glomerular basement membrane nephropathy. Am J Nephrol 1996;16:412-6.

2. Ding JY, Ibañez D, Gladman DD, Urowitz MB. Isolated hematuria and sterile pyuria may indicate systemic lupus erythematosus activity. J Rheumatol 2015;42:437-40.

3. Alain Prual, Hamani Daouda, Michel Develoux, Bertrand Sellin, Pilar Galan, Serge Hercberg. Consequences of Schistosoma haematobium infection on the iron status of schoolchildren in Niger. Am J Trop Med Hygiene 1992;47:291-7.

4. David JB, Fergus SM. Egg output stability and the epidemiology of Schistosoma haematobium Part II. An analysis of the epidemiology of endemic $S$. haematobium. Transactions Royal Soc Trop Med Hygeine 1973;67:491-500.

5. McCullough FS. The distribution of Schistosoma mansoni and $S$. haematobium in East Africa. Tropical Geog Med 1972;24:199-207.

6. Leshem E, Meltzer E, Marva E, Schwartz E. Travel-related schistosomiasis acquired

Laos. Emerging Infect Dis 2009;15:1823-6.

7. Rugemalila JB. The impact of urinary schistosomiasis on the health of two community populations living in endemic areas in Tanzania. Trop Geogr Med 1979;3:375-80.

8. Kinoti G. Observations on the transmission of Schistosoma haematobium and Schistosoma bovis in the Lake Region of Tanganyika. Bull WHO 1964;31:815-23.

9. Mas-Coma S, Valero MA, Bargues MD. Climate change effects on trematodiases, with emphasis on zoonotic fascioliasis and schistosomiasis. Vet Parasitol 2009;163:264-80.

10. Steinmann P, Keiser J, Bos R, Tanner M, Utzinger J. Schistosomiasis and water resources development: systematic review, meta-analysis, and estimates of people at risk. Lancet Infect Dis 2006;6:411-25.

11. Kosinski KC, Bosompem KM, Stadecker MJ, Wagner AD, Plummer J, Durant JL, et al. Diagnostic accuracy of urine filtration and dipstick tests for Schistosoma haematobium infection in a lightly infected population of Ghanaian schoolchildren. Acta Trop 2011;118:123-7.

12. Mohammad KS, Bdesha AS, Snell ME, Witherow RON, Coleman DV. Phase contrast microscopic examination of urinary erythrocytes to localize source of bleeding: an overlooked technique. J Clin Pathol 1993;46:642-5.

13. Doenhoff MJ, Cioli D, Utzinger J. Praziquantel mechanisms of action, resistance and new derivatives for Schistosomiasis. Curr Opin Infect Dis 2008;21:659-67.

14. Wynn TA, Thompson RW, Cheever AW, Mentink-Kane MM. Immunopathogenesis of Schistosomiasis. Immunol Rev 2004;201:156-67.

15. Midzi N, Sangweme D, Zinyowera S, Mapingure MP, Brouwer $\mathrm{KC}$, Kumar N, et al. Efficacy and side effects of praziquantel treatment against Schistosoma haematobium infection among primary school children in Zimbabwe. Trans R Soc Trop Med Hyg 2008;102:759-66. 